University of Louisville

ThinkIR: The University of Louisville's Institutional Repository

Electronic Theses and Dissertations

$5-1922$

\title{
The effect of heat on the resistance of varnish.
}

Leonard C. Brecher 1900-

University of Louisville

Follow this and additional works at: https://ir.library.louisville.edu/etd

\section{Recommended Citation}

Brecher, Leonard C. 1900-, "The effect of heat on the resistance of varnish." (1922). Electronic Theses and Dissertations. Paper 146.

https://doi.org/10.18297/etd/146

This Master's Thesis is brought to you for free and open access by ThinkIR: The University of Louisville's Institutional Repository. It has been accepted for inclusion in Electronic Theses and Dissertations by an authorized administrator of ThinkIR: The University of Louisville's Institutional Repository. This title appears here courtesy of the author, who has retained all other copyrights. For more information, please contact thinkir@louisville.edu. 
UN IVERS ITY OF IOUISVILIE.

THE EFFECT OF HEAT

ON THE RESISTANCE OF VARIISH.

\author{
A Dis sertation \\ Submitted to the Faculty \\ In Pàrtial f'ulfillment of the \\ - IASTER OT SCIEUTCE. \\ Depertment of Chemistry \\ by \\ Ieonard C. Brecher. \\ 1922.
}

of the Graduate School of Arts and scienoes

Requirements for the Degree of 
THE EFFECT OF HEAT ON THE RESISTANCE OF VARNISH. INTRODUCTION.

Varnish and its use has been known since ancient times. Altho the knowledge of varnish has been attributed to the Japanese as early as 500-600 B.C., Tschirsch and A.D. Dtevens say that the Japs did not possess this art originally, but that they probably acquired it from the continent during the third century. Nevertheless, varnish did not come into general use until the midale ages. In the 12 th century, a monk by the name of Theophilus published the first directions for making an oil varmish, but it was not until 1790 in England, and between 1820 and 1830 in France and lermany, that a factory was established for the cormercial producti onoof varmish?

In general, a varnish may be defined as a homogeneous, sticky, viscous solution of resins, of a colloidal nature, which when applied to a surface in a thin coat, dries to a hard, smooth, glassy surface. The color of varnish varies considerably, depending on the grade and on its use. Pale vornishes are generally sought, yet there are many dark varnishes of excellent 
quality. The following scale gives an idea of the degree of color of varnigh.

A solution of $0.25 \mathrm{~g} \mathrm{~K}_{2} \mathrm{Cr}_{2} \mathrm{O}_{4}$ in $100 \mathrm{~g}$ pure concentrated $\mathrm{H}_{2} \mathrm{SO}_{4}$ is equivalent to $a$ very light varmish.

solution of $2.00 \mathrm{~g} \mathrm{~K}_{2} \mathrm{Cr}_{2} \mathrm{O}_{7}$ in $100 \mathrm{~g}$ pure coneentrated $\mathrm{H}_{2} \mathrm{SO}_{4}$ is equivalent to a medium vamish.

$\Delta$ solution of $4.00 \mathrm{~g} \mathrm{~K}_{2} \mathrm{Cr}_{2} \mathrm{O}_{7}$ is $100 \mathrm{~g}$ pure concentrated $\mathrm{H}_{2} \mathrm{SO}_{4}$ is qquivalent to a dark varnish.

Varnishes may be divided into two main classes, according to the manner in which the film dries. The varnishes of the first class, which is the largest an most important, are known as oll varnishes. These varnishes dry mainly by the oxidation of the oil, which forms a tough, elastic film. Tho secondary drying in these oil varnishes is caused by the evaporation of the volatile vehicle, and by the polymerization of the constituents. On the whole, the drying of an oil varnish is of a chemical nature. The varnishes of the second class are called spirit varnishes. These ary merely By the evaporation of the solvent, and there is practically no chemical action. The gum is transferred from a lump form into a thin sheet by means of the solvent. The most important example of this class is shellac, which is the hardened secretion of the lac insect, dissolved in alcohol. 
Since my work hes been based on oil varnishes and since the general usage of the term"varnish" implies an oil varnigh, I shall speak only of oil varnishes and use the term "varnish."

Varnish generally contains four ingredients. 1-Resin, 2-Urying o1l, 3-rolatile thinner, 4-עrier. The resing are numerous and vary from the hardest, such as amber and zanzibar, down to the softer ones, such as South American and Cochin China. Some of the more widely used resins, or "gums" as they are known in comrerce, are congo and Kauri, which are of medium hardness.

The oile which receive the greatest use are first and foremost, linseed oll, and secondly, Tung or China Wood Oil. IInseed oil hes always been, and still is, the standard oil in varnish maing. It is only in the last decade that Tung oil he come into prominence. It is unexoelled for some purposes, especially in the manufacture of cheap rosin varnishes. Cold pressed walnut and poppy seed oils are also used to a slight extent, and any other oil could be used that contained a high percentage of Iinolenic, 1so-linolenic and Iinolic acids. Stated in another manner, any oil haing 
an iodine number over 120 would be admissable, tho linseed oll must have a minimum I number of $178 .^{4}$

The volatile thinners used are many, and differ according to the neture and uses of the varnish. Spirits of turpentine and wood turpentine are used, tho they polymerize in drying, giving a soft film which tends to make the varmish tacky. Fetroleum spirits, benzene, denatured alcohol and wo od alcohol also find wide usage. Without the adaition of a volatile thinner, the solution of the resin in oil would be too viscous to apply properly.

The driers for varnish are both of an organic and inorganic type, and their action is of a catalytic nature. The inorganic driers are the oxides of lead and manganese, which must be of a high quality in order not to injure the varnish. The iromirent organic driers are salts of lead and manganese resinetes and linolates. Lead driers in linseed oil vamishes increase the moisture absorption and the whitening of the film when it is exposed to water. In polymerized oils, lead driers increase the resistance of the film to water, but they also increase the emulsification properties of the vamish much more than do manganese..$^{5}$ It has also been found that lead driers increase the turbidity of a vamish more than 
other ariers do.b In general manganese is less injurious than lead, but it takes only a small amount of any arier, usualiy about .01-2\%. ${ }^{7}$

In making varnishes, great care must be taken in the melting and the dissolving of the resing. From $10-25 \%$ of the original resin must be distilled before the residue will dissolve in the vamish vehicles. ${ }^{8}$ the resins are us ually crushed to pea size and from 100150 lbs. are placed in a cylindrical, flat bobtomed copper kettle about the depth of its diameter. The kettle is placed on an iron truck which is rolled over a coke fire just below the level of the floor. The "gums" are then melted and it is dmring this process that the volatile portions are lost, tho some factories recover the distillate, which is known as copal oil. Hot boiled oil is now added and the mixture of ofl and resin is cooked and the driers are added. When the mixture has reached the right consistency, the kettle is withdrawn and allowed to cool. Then it is properly reduced with the volatile thinners, such as benzine and turpentine. ${ }^{10}$ In England with the better grade of varnishes, the practice is to allow the varnish to a ge from six months to geveral years, in order to allow any dirt or "foots" to settle. In the United states, the modern method is 
to pump the varnish to a centrifuge, and then let the varnish stand for a period of three to six months.

The quality and nature of the varnish depends as much on the proportion of oll used as it does on the kind of resin. The color of the varnish will be paler if the resins heve been well selected and the oil used is from ripe seed and is properly bleached. The herdness of the varnish depends lst, on the type of resin, and 2nd, on the amount of oil used. l'he more oil used, the softer will be the resulting film. This is due to the ture of linoxyn, which is tough and elastic. Brilliancy also depends both on the type of "gum" and on the amount of oil used. This is due to the fact that the index of refraction of the oll is less than that of the resin. The greater the proportion of resin, the greater will be the brilliancy.

Varnishes that contain less than 12 llons of 017 to 100 Ibs. of "gum" are called "short." These varnishes are hard and brilliant and are capable of being rubbed and polished. They are always used for interior work as they are not resistant enough to weathering. Those varnishes contalning 20 gallons or more of oil are termed "Iong" varnishes. Due to the larger percentage of linoxyn, the end product of linseed oil oxidation, 
they are tough and elastic and capable of withstanding moisture. Varnishes of this type, such as "sper varnish", while they have gained impermeability, have lost the brilliancy of a "furnitare varmish."

As a result of the complexity of varnish constituents, there is no general method of analysis in wide use. The tests are largely physical, and are based on "performance" rather than on chemical composition. The manufaoturer who purchases varnish wants to know how the varnish w111 "stand up" and act, so this information is ascertained by practical tests. However, if the composition of a varnish must be known, an approximation can be made.

Upon investigation of the various methods for the analysis of varn $1 s^{\prime 2},{ }^{2}$ believe that the best scheme yet published is that one given by Holly. 13 This, or any other proceedure, to be of value, must heve extensive analytical data with wich to compare the results. 'hat 1s, the values on a great number of varnishes of known composition must be at hand in order that the results shall have a meaning.

the common physicel tests are as follows: ${ }^{14}$ 1. The dried varnish film is immersed in water for a number of hours. Varnishes of appor grade or of little 
oil turn white more quickly than others.

8. Whe varnish film is arled on glass or white onameled tin and the color of the film is compared to that of the standard. The time of arying "dust free" and "hard" is noted $a$ is also the conaition of a freshly out edge. If the edge is brittle and produces dust, a short varmish is indicated, but if the edge is elastic and ragged, a long varnish is ind icated.

3. The viscosity is ny times determined by the air bubble me thod. 15 the varnish is placed in a bottle and the bottlo inverted. The time that it takes the air bubble to $\mathrm{rlse}$ is compared to that of a standard sample which is inverted at the same time. As standards, a series of mineral lubricating oils is taken, each oil representing a known viscosity. This method is quick, and in the hands of an experienced person is accurate for all practical purposes. However, for scientific work, a viscometer must be used. All Gravity types are inaccurate. For research work the Herschel modification of the Bingham \& Green Plastometer is recommended, but for fioneral industrial work the MacMichael or Doolittle torsional viscometers are best. 16 4. But the main test of a vamish is the manner in which it acts in use. Accordingly Government and 
other specification are allowing much more latitude than formerly in the composition of vamish. AB long as the varniah will "otand up" under the required conditions, that is all the purchaser cares about, consequently the chemical analysis of a varnish is a secondary matter. It is only when a varnish is to be dupli"cated or compared, that the value of a chemical analysis is evident. ${ }^{17}$

In order to determine the physical propertieg of the vamish, the manufacturer applies it to panels so as to parallel the conditions in the factory or place in which it is to be used. 18 Teste which are applied to a varnish just after the film has dried, should be repeated after a durati on of about two woeks. In fact, Dr. A. F. Iaurie states that a varnish film does not attain its maximum hardness until it is about twelve months old. 19 The varnish wich appears to be at first the best of several others, may, after the lapse of time be a poor varnish. This varlation is generally caused by the type and the amount of arier used. 'the film which may appear elastic at flrst may resolve itself into a lustreless or brittle one. Adulterants or excess of drier may produce serious defects. It is a generally established fact that at different states of drying or 
at different ages of the fllm, there is a difference in the properties of the dried coat. Iikewise it is agreod that a rise in temperature hastens the drying time. This is due to the increased rate of evaporation of the volatile thinner and to the increased catalytic aotion of the "oxygen carriers" or driers. Then the question is raised, "what effect he $\mathrm{s}$ this rise in temperature on the properties of the film?" It would seem that an increased temperature would increase the herdness and the brittleness of the film and perhaps by reducing its elasticity, make the film less durable for some types of work. In order to establish this theory the following experiments were mo.

\section{EXPER DMENIAI.}

In order to determine the effect of chemical action on heat-treated varnish, a series of varnigh flims was de at various temperatures, ranging from alr temperature $\left(70^{\circ} \mathrm{F}\right)$ to $\left(220^{\circ} \mathrm{F}.\right)$ After a number of trials on films which had been prepared previously, a solution of tenth-normal sodium hydroxide (N/10 NaOH) was adjudged to be the best reagent of several acids and alkalies of various strengths. The films were made on small porcela in dishes of uniform size, and loc of high grade rubbing 
Varnish was flowed into each one. The varmish in the dishes was dried at the determined temperature for 24 hrs. and then allowed to rest at rom temperature for another $24 \mathrm{hrs}$. At the end of this period $10 \mathrm{cc}$ of $\mathrm{N} / 10 \mathrm{NaOH}$ were put on each film. These dishos together with a blank sample were then put under g glas cover for $24 \mathrm{hrs}$. Lt this time the film was washed free from alk 1 and the alkali was titrated with $\mathrm{N} / 1 \mathrm{OHCl}$, using phenolphthalein as the indioator. From this titration the amount of alkali that interacted with the varnish film was determined, and is exprest in the table as follows: 
TABLE NO.1

Dish Temp. No. of ce

Remark.

$4922 \quad 3.60 \quad$ Hilms moveable with finger and

$5022 \quad 3.70$ wrinklod before adding alkali.

$3733 \quad 3.20 \quad$ Films moveable with finger and

$3833 \quad 3.25$ wrinkled before adding alkali.

$3340 \quad 3.45$ Films moveable with presgure of

$34 \quad 40 \quad 3.35$ finger \& slightly wrinkled before adding alkali.

$2948 \quad 2.00$ Films firm to touch, wrinklod af-

$30^{\circ} \quad 48 \quad 2.65$ ter exposure to alkall.

$45 \quad 57 \quad 3.25 \quad$ Films wrinkled after exposure to

$4657 \quad 3.00$ alkali. Lbout $\frac{1}{2}$ crlspy and $1008 \theta$.

$41 \quad 650.30$ Films firm to touch. Smooth a1-

$42 \quad 65 \quad 0.45$ ter exposure to alkali, with small soft spots.

$3 \quad 75 \quad 0.35 \quad$ Film smooth after exposure to

$4 \quad 75 \quad 0.30 \quad$ alkali.

$580 \quad 0.15 \quad$ Film smooth. F'ew small blisters

$680 \quad 0.20$ after heating. Alkali had no visible effect.

$9 \quad 85 \quad 0.20 \quad$ Film smooth. Darker after heating.

$1085 \quad 0.20 \quad$ Alkali had no visible effect.

$1394 \quad 0.20 \quad$ Blistered \& films darkened after

1494 - heating. Alkali had no visible effeo

$17 \quad 103 \quad 0.15 \quad$ Films smooth and darkened as if they

$18 \quad 103 \quad 0.15$ had been burned. Alkali had no v1sible effect. 
Considerable difficulty was experienced in the control of the temperature. The volatile constituents of the varnish seemed to affect the thermostatic oontrol of the oven causing a rise in the temperature. The temperature would remain constant until the introduction of volatile terial caused the temperature to rise from $10 \%$ to 15\%. Lt $100^{\circ} \mathrm{C}$ there was only a $3^{\circ} \mathrm{C}$ increase. After three or four hours the temperature would gradualiy fall to its former level or become constant at some new lower level. The temperatures given about are the average temperatures to which the film was exposed. As was to be expected, there was more variation at high temperatures than at low temperatures. Any volatile substance such as benzene, ethyl ether, or petroleum ther produced corresponding rises in temperature. It also appears probable that the volume of the oven contents has an influence on this phene omenon of vapor pressure.

A second series of vamish films was dried at the same time with the dishes of the first series, and was treated in the same manner. However, two weeks airdrying were allowed, after the dishes hod been heated, and before the alkali was added. The results obtained are expresed in Table No. 2. It will be noted that the films dried at low temperatures wrinkled on standing. 
This wrinkling oc cured in the center of the $f$ ilm where the varnish was about 1 laM. deep. There are a number of theories on the wrinkling of vamish films. vollman 20 claims that highly volatilo thinners are apparently cpnancive to wrinkle formation and that white light causes more wrinkles than red or no light. On the other hand, Wolff says that light of long wave lengths (red or orange) appears to produce wrinkles, while that of short wave lengths (colorless and blue) favors smooth drying. Again, Ragg disputes this theory and states that wrinkling is due to heat swelling the undercosting. 22 Whatever may be the cause, the higher temperatures oeem to have hardened the coating or to have dried it so thor-. oughly that no wrinkling could hove taken place. 
TABIE NO.2

\begin{tabular}{|c|c|c|c|}
\hline$\underset{\#}{\operatorname{Dish}}$ & $\underset{C^{\circ}}{T e m p}$ & $\begin{array}{l}\text { No. } 00 \text { of } \\
\text { N/10 NaOH }\end{array}$ & Remarks. \\
\hline $\begin{array}{l}51 \\
52\end{array}$ & $\begin{array}{l}22 \\
22\end{array}$ & $\begin{array}{l}6.00 \\
5.45\end{array}$ & $\begin{array}{l}\text { Films clear \& smooth after } 2 \text { weeks, } \\
\text { but moveable to touch. All of films } \\
\text { soft \& wrinkled after adding alkali. }\end{array}$ \\
\hline $\begin{array}{l}39 \\
40\end{array}$ & $\begin{array}{l}33 \\
33\end{array}$ & $\begin{array}{l}4.20 \\
4.15\end{array}$ & $\begin{array}{l}\text { Filme slightly wrinkled \& moveable } \\
\text { to touch before adding alkali. About } \\
\text { s of film loose \& wrinkled after. }\end{array}$ \\
\hline $\begin{array}{l}35 \\
36\end{array}$ & $\begin{array}{l}40 \\
40\end{array}$ & $\begin{array}{l}4.10 \\
4.10\end{array}$ & $\begin{array}{l}\text { Filme slight ly wrinkled \& Hard be- } \\
\text { fore adding alkali.About } \frac{1}{2} \text { wrikn- } \\
\text { led \& white after adding alk li. }\end{array}$ \\
\hline $\begin{array}{l}31 \\
32\end{array}$ & $\begin{array}{l}48 \\
48\end{array}$ & $\begin{array}{l}3.65 \\
3.00\end{array}$ & $\begin{array}{l}\text { Filmo wrinkled after } 2 \text { weeks but } \\
\text { hard \& clear. About } \frac{1}{2} \text { loose \& crisp } \\
\text { after adding alkali. }\end{array}$ \\
\hline $\begin{array}{l}47 \\
48\end{array}$ & $\begin{array}{l}57 \\
57\end{array}$ & $\begin{array}{l}4.40 \\
4.00\end{array}$ & $\begin{array}{l}\text { Films slightly wrinkled but firm to } \\
\text { touch before ading alkali, about } 2 / 3 \\
\text { loose afterwards. }\end{array}$ \\
\hline $\begin{array}{l}43 \\
44\end{array}$ & $\begin{array}{l}65 \\
65\end{array}$ & $\begin{array}{l}5.50 \\
5.85\end{array}$ & $\begin{array}{l}\text { Films smooth before adding alkali, } \\
\text { about } 2 / 3 \text { wrinkled \& soft after. }\end{array}$ \\
\hline $\begin{array}{l}53 \\
54\end{array}$ & $\begin{array}{l}73 \\
73\end{array}$ & $\begin{array}{l}0.50 \\
0.25\end{array}$ & $\begin{array}{l}\text { Films smooth \& hard before adding } \\
\text { alkali.Slightly wrinkled but firm } \\
\text { afterwards. }\end{array}$ \\
\hline $\begin{array}{l}7 \\
8\end{array}$ & $\begin{array}{l}80 \\
80\end{array}$ & $\begin{array}{l}0.10 \\
0.25\end{array}$ & $\begin{array}{l}\text { Films blistered slightly.Alkali had } \\
\text { no visible effect. }\end{array}$ \\
\hline $\begin{array}{l}11 \\
12\end{array}$ & $\begin{array}{l}85 \\
85\end{array}$ & 0.30 & $\begin{array}{l}\text { Films blistered slightly and dark- } \\
\text { ened. Alk i had no visible effect. }\end{array}$ \\
\hline 15 & $\begin{array}{l}94 \\
94\end{array}$ & $\begin{array}{l}0.10 \\
0.15\end{array}$ & $\begin{array}{l}\text { Films darkened. } \\
\text { ible effect. }\end{array}$ \\
\hline 19 & $\begin{array}{l}103 \\
103\end{array}$ & $\begin{array}{l}0.00 \\
0.10\end{array}$ & $\begin{array}{l}\text { Films darkened. Alkali had no vis } \\
\text { ible effect. }\end{array}$ \\
\hline
\end{tabular}


After washing the films, which had been exposed to the higher temperatures, free from alkali, the thin portions of the film on the edge of the dish curled up and peeled of $f$. While the alkali was still on them, they appeared to be unaffected, but a few minutes after washing the peeling commenced. This is possibly due to the fact that the heat and the thinness of the film caused the varnish to be greatly oxidized and polymerized, and this together with the action of the alkali produced a brittieness in the film. The force of the washing may then have caused the peeling.

It will be noted from a comperison of table No.l with table No.2 that more alkali was required to react with a film that had been dried two weeks than was required for one that was acted upon immedately. This is different from what would be expected, for the film having the longest time to dry would be harder and drier, consequently this film would be expected to be more resistant to alkali than a more recent film. To test this phonomenon further, three sets of films were prepared at intervals of about two weeks. The films were all aried at room temperature which a veraged about $22^{\circ} \mathrm{C}$. At the end of seventy two hours, $10 \mathrm{cc}$ of $\mathrm{N} / 10 \mathrm{NaOH}$ were added to two of the films and after $24 \mathrm{hrs}$. this alkali was 
titrated with $\mathrm{N} / 10 \mathrm{HCl}$. One week later, the two remaining dishes in each set were treated in the same manner. The results are as follows:

$$
\text { TABLE NO.3. }
$$

After ne hrs.

Ho. No. I week and $72 \mathrm{hrs}$.

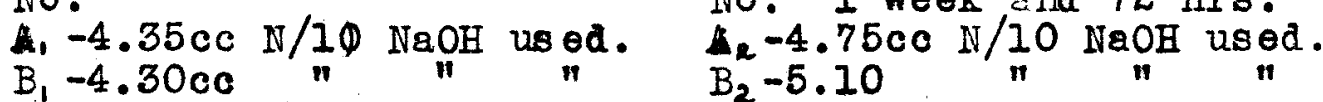
$\begin{array}{llllllll}C_{1}-4.35 c c & " & " & \text { " } & C_{2}-5.85 & " & n & \text { " } \\ D_{1}-4.55 c c & \text { " } & \text { " } & \text { " } & D_{2}-5.35 & \text { " } & \text { " } & \text { " }\end{array}$

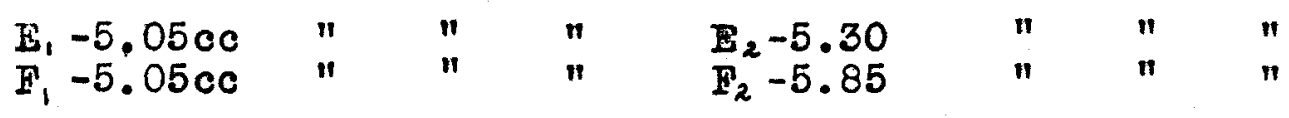

In order to determine the effect of heat on the elasticity and the water-resistant qualities of varnish, the following series of films were made on tin plates. Tin piated sheet iron which had been enameled white on one side was cut into strip 5" long and $2 \frac{1}{2} "$ wide. Four pieces were dipped into the high grade finishing or "rubbing" varnish used above, and four others were dipped into a varnish containing a small amount of barytes and known to the trade as "surfacer" or "Ist coater". After the strips hed drained they were suspended in the oven at the desired temperature for 24 hours..$^{23}$ The stripe were then allowed to rest at air temperature for another 24 hour period. At this time one tin strip bearing the "surfacer" varnish and one strip bearing the rubbing varnish 
were bent double over a $3 \mathrm{~mm}$. rod wi th the enameled surface on the outside. Exactly two weeks later two more from the set of eight were bent in the same menner and the behavior of the dried film, both on the convex and concave sides of the bend, was noted.

\section{TABIE NO. 4. \\ Films 48 hours dry.}

Fin Strip Temp. Condition at
co $^{0}$ convex bend.

Condition at concave bend.

\#8 Fin.

\#8 Sur.

\#7 Fin.

\#7 Sur.

22

22

*8 Fow light hair lines

8 Lus tre Dulled

347 l'ew light ha ir line

347 Iu tre Dulled

\#6 Fin.

44

44

\#5 Fin.

$$
55
$$

$556 \mathrm{H}$ ew ha ir lines

杠 Fin. 58

583 Hair lines \& scaled

Iustre Dulled. Loose \& scaled

\#I Sur. 69

\#2 Fin. \#2 Sur. 69

\#4 Fin. \#4 sur. 78 78

\#3 kin. \#3 sur.
6

5 Few hair line

4 Few heir lines

2 Fight hair lines

1 Light ha ir lines

Iustre Dull ed. Loose \& scaled

Ius tre Dulled Loose \& scaled.

Hair Iines Ioose \& scaled

Hair lines \& scaled IoOse \& scaled

Many hair lines \& scale Ioose \& scaled.

Hair lines.

Loose \& scaled

4 Few Hair lines

- Iustre Dulled

5 Hair lines \& sceled

Loose \& scaled

* Numbered in or der of their being most affected. 
TABLE NO. 5 .

Films 16 days old.

Tin Strip Temp. Condition at

Dondition at $c^{\circ}$ convex bend.

concave bend

\#8 Fin. 22 *8 k'ew light he ir lines

\#8 Sur. 228 Iustre Duliod

Iustre Dulled

\#7 Fin. $34 \quad 7$ Few light ha ir lines

Loose \& scaled

\# sur.

347 Lustre Dulled

Ius tre Dulled

Ioose \& scaled

\#6'in. 446 t'ew hair lines

\$or.

446 Iight ho ir lines

Iustre Dulled

Loo se \& scrled

\#5 tin. $55 \quad 5$ t'ew ha ir lines

\#5 sur.

55

5 Iight hair lines

\#1 Fin.

58

4 Hair lines \& scal $\theta$ d

\#1 sur.

58

4 Hair lines \& scaled

Iustre Dulled

Loose \& scaled

\#2 Fin.

69

3 Hair lines \& scaled

\#2 Sur.

3 Hair lines \& 8 cal ed

lrany hair lines \& sca Ioos $\theta$ \& scal $\theta d$

\#4 Fin.

78

2 Jany ha ir lines \& 8 caled Many hair lines \& sca \# Sur. 78

1 wany hair lines \& scaled loo se \& scaled

\#3 Fin.

89

1 Many hair lines \& ocaled lfany hair lines \& sca \#3'sur.

2 llany hair lines \& scaled Ioose \& scaled

* Numbered in order of their being most affected.

The varnish did not adhere so well to the

tinned side as it did to the side of the strip which had been enamelod. This accounts for the fact that the concave side was affected more than the convex side of the bend.

Two weeks after the last film of the series Was dried, each film was scratched with a knife in or- 
der to determine the influence of heat on the elasticity. Elastic or "long" varnishes will "ribbon" under the knife blade, wherees "short" and hard vamishes chip or "dust". The "surfacer" was so short that no difference could be detected between the effects of the various temperatures. The rubbing varnish, which was short by its nature, did not show any merked differences, yet the higher temperatures produced a harder $11 \mathrm{~lm}$, as determined by the conditions of the cut edge.

To determine the water-resistant qualities of the various films, one strip of $t$ in was taken from each set. 11 the strips were placed in city water at the same time and at least two weeks after the last film had been prepared, so that the films were thoroughly dried. The finishing vamish, being of a higher grade than the "surfacer"I required more time to show the effect and so the two varnishes were treated separately. 
TABLE NO.6.

Finishing Varnish-Continuous Exposure.

$\begin{array}{lllll}\text { Strip. Temp.0 After } 9 \text { hrs. } & \text { After } 17 \text { hrs. } & \text { After } 21 \text { hrs. } \\ \# 8 & 22 & \text { Slightly white } * 2 \text { White } & \text { *2 White } \\ \# 7 & 34 & \text { Slightly white } & 1 \text { White } & 1 \text { White } \\ \# 6 & 44 & \text { Not affected } & 3 \text { Fairly white } 3 \text { White } \\ \# 5 & 55 & \text { Not affected } & 4 \text { slightly white } 4 \text { Slightly white } \\ \# 1 & 58 & \text { Not affected } & 5 \text { slightly white } 5 \text { Slightly white } \\ \# 2 & 69 & \text { Not affected } & 6 \text { Slightly white } 6 \text { slightly white } \\ \# 4 & 78 & \text { Not affected } & 7 \text { Very " "white } 7 \text { Very " white } \\ \# 3 & 89 & \text { Not affected } & 8 \text { Not affected. } 8 \text { Whitish cast. }\end{array}$

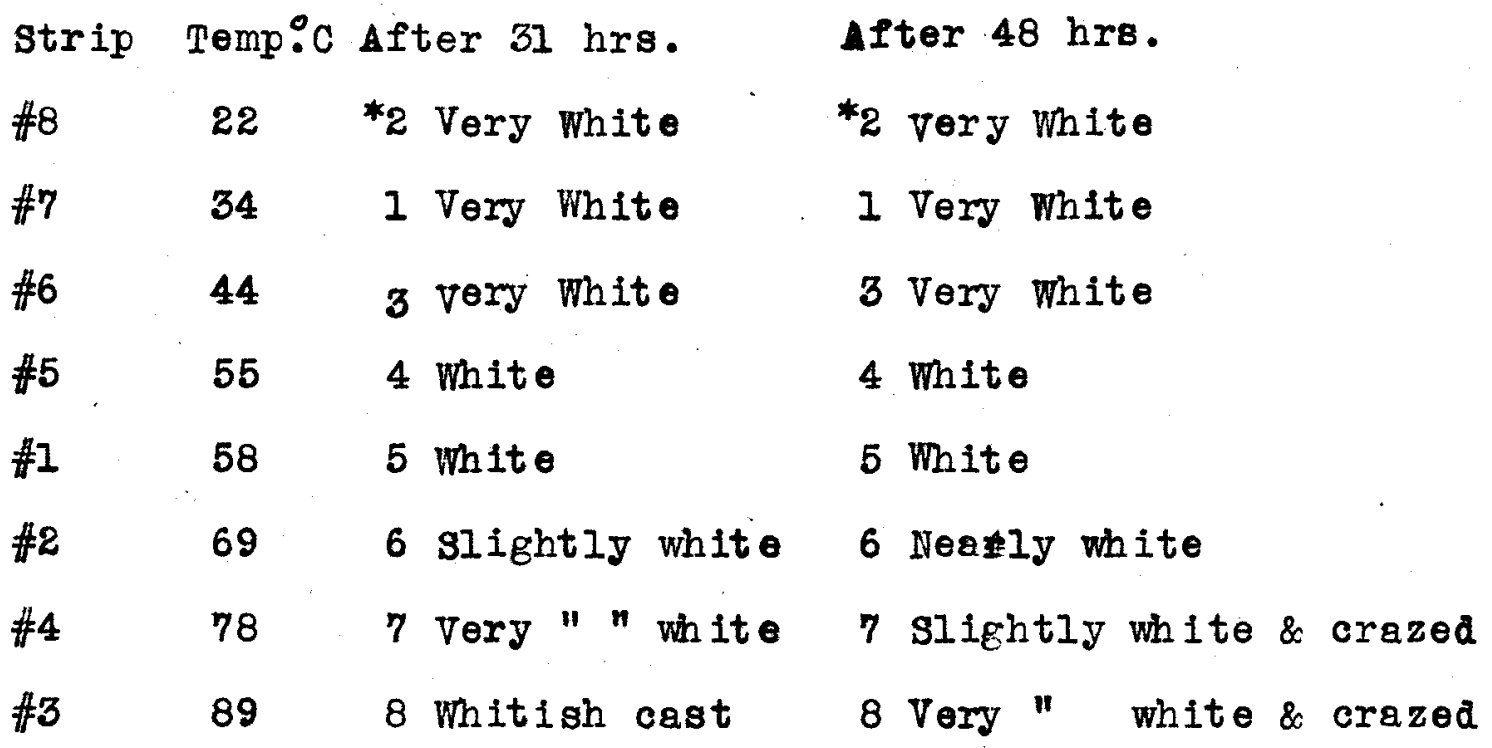

* Numbered in order of their greatest whiteness. 
TABIE NO.?.

Surfacing Varmish--Continuous Exposure.

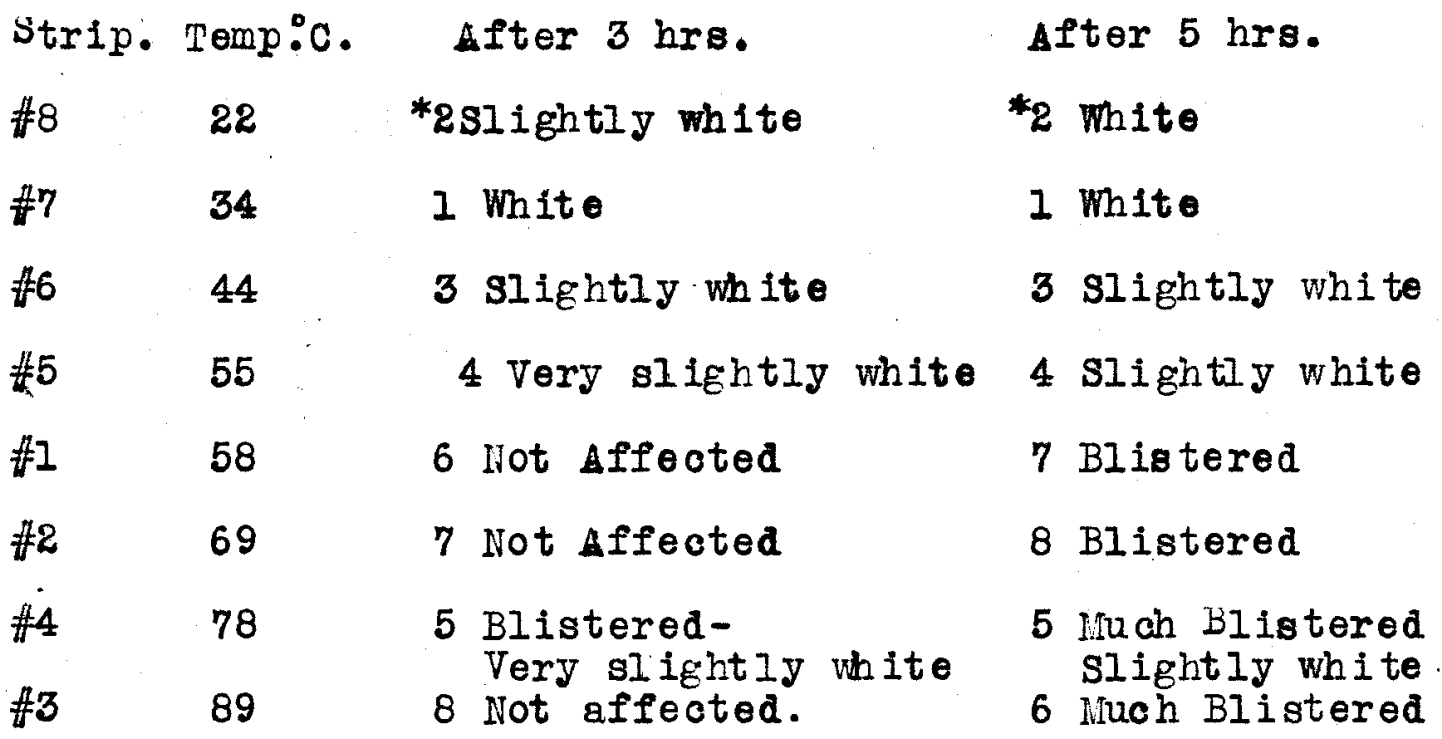

Strip. Temp:C. After $8 \mathrm{hrs}$.

After $14 \mathrm{hrg}$.

\#8

22

*2 White

$\neq 6$ very white

隹 7

34

1 Wite

5 White

\#6.

44

3 White

7 Very Wite

$\# 5$

55

4 Slightly white

8 White

\#1 58

\#2

7 Slightly $\mathrm{Bl}$ is tered

3 White \& Blistered and " $"$ White

8 Slightly Blisterod and $n$ "White

壮 78

\#3

6 Slightly White 竞 washed of $f$

5 Slightily white $2 / 3$ washed off

4 White \& Blistered

2 Wite

$2 / 3$ washed off

89

1 All off.

\footnotetext{
* Numbered in order of their greatest whiteness. Frumbered in order of their being most affected.
} 
All observations were made on the tinned side of the strip as the whitening of the varnish was not apparent against the wite background of the enameled side. Block claims that if a vamish does not turn permanently white when it is exposed to water, the varnish does not necessarliy lack durability. 24 Dellaelo suggesta that the films might act as semi-permeable membranes, while Wolff claims that al tho the film is waterproof, yet it is not

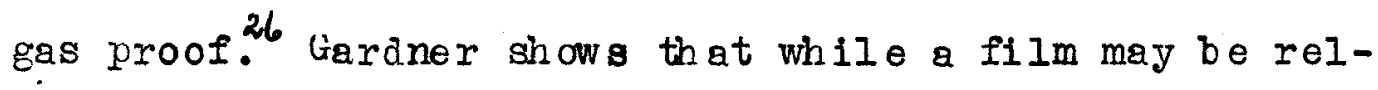
atively moisture-proof, it may not be water-proof. ${ }^{27}$.

\section{CONCLUSIONS.}

Tables \#1 and \#2. Higher temperatures produce a varnish f1lm that is more resistant to the ac-. tion of alkall then lower temperatures produce.

Tables \#1-\#2 and \#3. With the particular varnish und er investigation, time produces in the dried film, compounds which react with alkali.

Tables \#1 and \#2. Higher temperatures dry thick film more quickly and thoroughly than do low temperatures, thus preventing wrinkle formation.

Tables \#I and \#2. High temperatures cause a rapid evaporation of the volatile thinner and an evolu- 
tion of volatile products. Blisters are formed, thereby destroying the value of the film, tho this would probably not occur in a thin film.

Tables it and 45 . Higher temperatures produce a film that is less elastic then one produced by lower temperatures. 'l'here is apperently no difference between films bent immediately after the heat treatment and those bent after a lapse of two weeks. No conclusion can be drawn however, as the difference may be so slight that it cannot be detected by this method. Further investigation is indicated, using a long oil varnish.

Tables \#6 and \#7. Higher temperatures produce a film that is more resistant to water than films produced by lower temperatures. It is to be noted that while the varnish in table 36 resisted water for $48 \mathrm{hrs}$., yet this same vamish when exposed to weathering in a driving rain for 16 hrs., was completely washed from wo od panels.

It was also noted that higher temperatures produced a film that was more resistant to solvents such as alcohol, benzene and turpentine, than one produced by lower temperatures.

While these tests may hold true for just these particular varmishes, yet the results as a whole would seem capable of being applied to oil varmishes in general, since all oil vamishes are based on the same principles. 


\section{BIBL IOGRAPHY.}

1. Bottier and Sabin. German and American Varnish laking. Page 2.

2. Iivache and MoIntosh. Varnish Waterials and Oil Varnish Making. Vol. II. Page 120.

3. H.k. Gardner. Papers on Paint and Varnish. Page 135.

4. A.S.T.M. Specifications DII-15 and DI-15. for Iinseed Oil from N.A. Seed.

5. R.S. Morrell. The Water Absorbing Properties of Varnishes and paints. J.0il Color Chem. Assn.4,130-57-(1921)

6. P.0.Scribe. Ilurbidity in Varnish. Oil, Paint and Chemical heview. Vol.73-\#14,10(1922)

7. F.C. Wright. Iiquid Wriers. Oil, Paint and Chemical Revi ew. Vol.73t15,11(1922)

8. Iivache and McIntosh. Varnish Materials and 0il Varnish lila king. Vol II. Page 96.

9. A.H.Sabin. 'Heohnology of $\mathrm{P}_{Q}$ int and Varnish.

10. H. Gardner. Papers on Paint and Varnish. Page 141.

11. Iivache \& MoIntosh. Varnish Materials and 0il Varnish liaking. Vol.II, Page 121.

12. W.T.Pearce. Comparison of Various Methods of Analysis. Jour. Ind. and Eng. Chem.Vol.11, \#3,200 (1919).

13. Holley. Analysis of Paint Vebicles, Japans and Vamishes.

14. H.A.Gardner. Physical testing of Paint and Varmish. Circular \#122, Educati onal Bureau of Faint lifa mufacturers Assn. of U.S.

15. H.A.Garaner \& P.C.Holat. A Standaraized Apparatus for tir Bubble consistency test on Varnish.Circular \#128. Hiducational Bur eau. Paint Mfrs.Assn.of U.S. 
16. H.A. Uaraner \& E.U.Holdt. 'the lileasurement of the consiatency of Varnish. Circular H127. Hacational Bureau. Paint lifgrs. Assn. of U.S.

17. W.T.Fearce. The Woaring Quality of Hxterior Varnishes compared with their Physical and Chemical analysis. Jour. Ind. and bing. Chem. Vol.12, \#6. 552-5(1920)

18. H.A.Gardner. Papers on Paint and Varnish. Chap.XIV.

19. W.K.Schmidt. Froblems of the Finishing Room.Page 278.

20. H.Vollmann. The Wrinkling of Varnish Hilms. Farben-Zeitung 26, 56-58 (1920).

21. Hens Wolft. Influence of Colored light on the arying of jarnishes. Farben-Zeitung. 24,119(1919).

22. M.Ragg. Influence of colored Iight on the arying of Varnishes. Farben-Zeitung 24,1308 (1919).

23. Hans Wolff- A Method for testing Elasticity of Varnish. Farben-Zeitung 26,2587 (1921).

24. E.G.BIoch-Comperison of thrability and Water Resistance of Varnish. Lrugs, Oils \& Paints. 36,426 (1921).

25. A.DeWaele-Permeability of Paints and Varmishes. Chem. Trade Journal, 65,415-6 (1919).

26. Hans Wolff-Action of Oxygenated Water on Varnish Coatings. liarben-zeitung 24,961-2 (1919).

27. H.A.Gardner. Papers on Paint and Varnish.Chap.ZII. 